\title{
La “Gran Transformación” del Milagro MEXiCANO. A 20 años DEL TLCAN: DE LA ADOPCIÓN A LA ADAPTACIÓN
}

\section{Rolando Cordera*}

Fecha de recepción: 1 de agosto de 2014. Fecha de aceptación: 27 de noviembre de 2014.

\begin{abstract}
RESUMEN
Si bien la evaluación del Tratado de Libre Comercio de América del Norte (TLCAN) no puede reducirse a verlo como la fuente de todos nuestros males ni tampoco como como la panacea, no es posible dejar de señalar que tanto los resultados como el desempeño económico y social de México a lo largo de estos años, son ejemplo de la experiencia histórica de un cambio institucional drástico que no dio los frutos prometidos ni permitió la emergencia de estructuras y potencialidades que el país requiere para mantenerse como Estado nacional y democrático en medio de un proceso profundo de internacionalización.
\end{abstract}

Palabras clave: apertura comercial, cambio estructural asimétrico, vulnerabilidad social, pobreza, reconfiguración del poder.

Clasificación JEL: F13, F14, F15, F55, I31.

\section{The “Great Transformation" of the Mexican Miracle. 20 Years After nafta: From ADOPTION TO ADAPTATION}

\begin{abstract}
An evaluation of the North American Free Trade Agreement (NAFTA) should not reduce it to merely the source of all our problems, or, on the contrary, their panacea. Even so, we must not forget that the economic and social performance of Mexico in these past years is an example of the historical experience of a drastic institutional change that did not produce its promised outcome. Moreover, it did not allow the structures and potentialities that a country needs to remain a democratic nation-state to develop in the midst of a profound shift towards internationalization.
\end{abstract}

Key Words: Trade openness, asymmetric structural change, social vulnerability, poverty, reconfiguration of power.

\footnotetext{
*Facultad de Economía de la unAm, México. Correo electrónico: rolandocordera@mac.com
} 


\section{LA “GRANDE TRANSFORMATION” DU MIRACLE MEXICAINO. 20 ANS APRÈS LE TLCAN: DE L'ADOPTION À L'ADAPTATION}

\section{Résumé}

Si l'évaluation de l'Accord de libre échange nord-américain (TLCAN en espagnol) ne peut être réduite à voir celui-ci comme la source de tous les maux ni, au contraire, comme la panacée, il n'est pas non plus possible de ne pas signaler que les performances autant que la vie économique et sociale du Mexique au long des dernières années sont un exemple d'expérience historique de changement institutionnel radical qui n'a pas donné les fruits escomptés ni permis l'émergence de structures et potentialités dont le pays a besoin pour se maintenir comme État souverain et démocratique au milieu d'un profond processus d'internationalisation.

Mots clés: ouverture commerciale, changement structurel asymétrique, vulnérabilité sociale, pauvreté, reconfiguration du pouvoir.

\section{A “Grande TransformaÇáo” do milagre MEXicano. DOS 20 ANOS DO TLCAN: DA ADOÇÁO À ADAPTAÇÃO}

\section{Resumo}

Se bem a avaliação do Tratado de Livre Comércio da América do Norte (TLCAN) não pode se reduzir a vê-lo como a fonte de todos os nossos males nem, pelo contrário, como a panaceia; também náo é possível deixar de assinalar que tanto os resultados como o desempenho econômico e social do México ao longo destes anos são exemplo da experiência histórica de uma mudança institucional drástica que não deu os frutos prometidos nem permitiu o surgimento de estruturas e potencialidades que o país requer para se manter como Estado nacional e democrático em meio a um processo profundo de internacionalização.

Palavras-chave: abertura comercial: mudança estrutural assimétrica, vulnerabilidade social, pobreza, reconfiguração do poder.

\section{北美自由贸易协定二十年之后墨西哥奇迹大转型：从实施到适应}

摘要:

对北美自由贸易协定的评估，不能简单地把墨西哥所有的问题都归因于 它。与之相反, 也不能把它看作解决所有问题的神丹妙药。即便如此, 我 们不能忘记, 北美自由贸易协定生效后, 墨西哥经济和社会的表现是这种 剧烈的制度性变化的历史经历的例证，但这并未能产生预期效果。而且， 墨西哥也未能实现结构性变化, 以挖掘发展潜力, 促成墨西哥能够保持以 一个民主国家的身份实现深度的国际化。

关键词: 贸易开放度 不对称结构变化 社会脆弱性贫困 权力重构 


\section{INTRODUCCIÓN ${ }^{1}$}

Veinte años pueden ser vistos por el historiador o el tanguista como si fueran nada. Y tendrían sus razones. Sin embargo, los últimos dos decenios, en realidad la treintena, en nuestro caso constituyen un periodo social y económicamente significativo y definen una fase todavía no cerrada de nuestro desarrollo histórico: más de una generación de mexicanos ha nacido y crecido bajo el influjo de las transformaciones institucionales decididas entonces y nuestra evolución política y económica ha registrado mudanzas y contradicciones que, en principio, deben atribuirse a dichas decisiones.

Tiene razón Antonio Gazol cuando nos advierte sobre el error analítico y, agrego, el peligro político, de ver en el TLCAN la fuente de todos nuestros males o, por el contrario, la panacea para el salto cuántico hacia la modernidad y la prosperidad que sus promotores prometían y, en algunos casos, todavía insisten en prometer. Como lo postulara en su excelente texto "Sobre las 'culpas' del TLCAN", publicado en el suplemento de La Jornada de Morelos "El Correo del Sur", el Tratado debe ser visto como una parte de "una política económica derivada de una concepción de la sociedad y de la economía identificada como neoliberalismo" (Gazol, 2014).

La adopción de este enfoque doctrinario, que se ha convertido en una fórmula política e ideológica de alcances universales que marcó la época, sobre cuyas implicaciones advertimos con anticipación (Cordera y Tello, 1981), tuvo lugar antes de que el gobierno del presidente Carlos Salinas de Gortari hiciera del Tratado el propósito estelar de su estrategia de cambio estructural y, desde luego, de que se firmara en 1994.

Antes, no lo olvidemos, tuvieron lugar cambios institucionales de indudable profundidad y alcance, como la reforma al artículo 27 constitucional y la reprivatización de la banca que se había nacionalizado en 1982; modificaciones en las leyes del petróleo y la energía eléctrica; venta frenética de empresas públicas; prédica sin descanso sobre la magia del mercado, como sinónimo de modernidad, etcétera.

Este ensayo tiene el objetivo de analizar esa dinámica relación entre la trayectoria planteada para el cambio estructural desde el gobierno del presidente Salinas de Gortari y el TLCAN; posteriormente se estudian los resultados económicos y las dificultades políticas que fueron desarrollándose subrayando

1 Una versión previa fue presentada en el seminario "20 años del Tratado de Libre Comercio de América del Norte: viejos problemas nuevos desafíos”, realizada en el Departamento de Estudios de Posgrado de la Facultad de Economía de la unAM, 23 y 24 de enero de 2014. 
la vulnerabilidad social y la pobreza que le han acompañado; finalmente, se analiza el Tratado y los procesos de internacionalización, así como las amplias consecuencias que ello tiene sobre las configuraciones del poder.

\section{HACIA UN CAMBIO ESTRUCTURAL ASIMÉTRICO RESULTADO DEL TLCAN}

El TLCAN pronto se convirtió en la figura emblemática de la estrategia de cambio estructural emprendida años antes de su entrada en vigor, así como uno de los instrumentos por excelencia para apoyar la vasta operación de agit prop desplegada por el gobierno en su empeño por construir no sólo una trayectoria de crecimiento distinta a la que se había seguido, sino una hegemonía que efectivamente pudiera relevar, desplazar dirían no pocos, a la estrategia heredada de la Revolución mexicana en su fase desarrollista industrializadora dirigida por el Estado.

La evaluación del Tratado no puede hacerse por separado, salvo en una primera aproximación analítica. Tampoco se puede prescindir de los grandes propósitos recogidos en su preámbulo, a los que Gazol hace precisa referencia en su ensayo.

En apretada y apresurada suma, podríamos decir que el éxito exportador logrado en el periodo abierto por su firma, contrasta con el escaso grado de integración nacional alcanzado por esas exportaciones y, más en general, por el conjunto de la estructura productiva nacional. Podemos decir así, que la férrea dependencia del ritmo de crecimiento económico respecto de la capacidad para importar no ha sido en realidad superada y que, en todo caso, las recurrentes crisis de pagos externos que caracterizaron la era industrializadora y la llevaron a su crisis de deuda en 1982, se han evitado o modulado principalmente con cargo a una reducción de dicho crecimiento mantenida a lo largo del tiempo, hasta llevar al país al "estancamiento estabilizador" que se ha impuesto ya como trayectoria histórica en los últimos lustros.

Lo mismo puede decirse de los incrementos notables registrados en los flujos de Inversion Extranjera Directa (IED) en los primeros años del Tratado: su monto y dinámica contrastan y deben contrastarse con los reducidos índices de crecimiento económico y del empleo formal que marcan la época. También, con el magro aprovechamiento de dicha inversión en lo referente a la transferencia tecnológica y el impulso a la innovación.

Además, como bien lo expone Gazol, el Tratado no reconoce explícitamente la "evidente asimetría entre las partes... (ni) prevé mecanismo alguno para reducirla o, al menos, no acrecentarla”. Este reconocimiento debería haber 
sido el punto de partida para hacer del tratado un auténtico vehículo para el desarrollo, de México desde luego, pero de la región en su conjunto, para convertirse en una zona en proceso de integración propiamente dicha: lo que ha sucedido es una marcada desintegración productiva en el caso de México y una arrebatada integración regional sin cauces ni rumbo claros.

El Tratado implicó también la renuncia expresa al uso de las compras del sector público como instrumento para promover el crecimiento y la industrialización diversificada, como lo requiere un proceso de desarrollo propiamente dicho. Como sabemos, la anterior decisión acompaña otra renuncia, en este caso a condicionar la IED conforme a ciertos objetivos de desempeño, en materia de integración productiva o transferencia tecnológica.

Poco o ningún caso se ha prestado al hecho reconocido de que esta capacidad estatal de orientación y modulación de los flujos externos, en nuestro caso atraídos por la ampliación del mercado norteamericano, se ha probado fundamental en otras estrategias de apertura externa con fines de desarrollo interno, como lo muestran la experiencia china y coreana.

En estos aspectos, como lo ha señalado repetidamente Federico Novelo (2012), de manera expresa el Tratado introdujo tales limitaciones; sin embargo, hay que señalar que la manera tan peculiar de asumirlas no viene, al menos no directamente, ni de las "mejores prácticas" del comercio libre o administrado, ni de los propios teoremas que supuesta o realmente las inspiran.

En lo sustancial han derivado de la convicción, o de la "reconversión" si se quiere, de las elites dirigentes del Estado y los negocios de que el cambio institucional condensado en el TLCAN debería reflejar, a la vez que contribuir a reproducir, un profundo cambio cultural, ideológico y político (aunque en esto último privó hasta el final el dogma autoritario del Estado posrevolucionario), y que el entonces secretario de Programación y Presupuesto, Ernesto Zedillo, resumió en una sumaria condena de la política industrial. Esta sentencia fue popularizada por su compañero de gabinete, el doctor Jaime Serra Puche (en 1992), con el dicho de que "la mejor política industrial es la que no hay".

Sin duda, cambio estructural hubo y con él profundas mudanzas institucionales, constitucionales y no. También podemos registrar mutaciones en los modos de concebir y hacer negocios, consumir y tomar decisiones de ahorrar e invertir.

Junto con lo anterior, la economía hubo de inscribirse progresivamente en otro formato político, cada día más distante del que sirvió para imponer el cambio estructural y llevar al país a una pauta de relación con el exterior cada día más lejana de la que acompañó la era industrialista de México. Entonces, los criterios de soberanía solían ser explícitamente asumidos como compo- 
nentes centrales de las decisiones del Estado nacional y su evolución, luego, la soberanía pasó a ser vista y entendida, en el mejor de los casos, como una variable dependiente de los mercados, la competitividad y la globalización.

Ahora, el campo político recoge y reproduce una pluralidad política indudable, aunque su productividad en términos de gobierno o bienestar social sea cuestionada una y otra vez. La o las maneras de cómo el nuevo sistema político se ha acomodado, prácticamente sin chistar, a los criterios de evaluación y el estrecho abanico de opciones o alternativas para el desarrollo que dejan el Tratado y las interpretaciones que de él se hacen dentro y fuera del país, constituyen indicadores poderosos, aunque no necesariamente mesurables, de la manera como el cambio institucional caló en la estructura del poder.

Ésta, aunque de modo un tanto imperceptible, había empezado desde los años setenta a registrar cambios importantes, del mismo modo como lo hacían el propio carácter de la sociedad que recibió el cambio y los actores políticos a los que, en palabras de Rafael Segovia, les fue "otorgada" la democracia representativa.

Hasta la fecha, la política democrática se ha desplegado con disciplina notable dentro del marco de restricciones explícitas e implícitas consignadas por el Tratado, pero sobre todo por el conjunto de la estrategia económica adoptada al calor de las crisis de los años ochenta. Así, en el contexto de la política económica, no obstante la mencionada pluralidad, se implantó un peculiar "sentido de pertenencia" de las fuerzas políticas a los parámetros y restricciones que la mudanza económica de fin de siglo trajo consigo.

Gráfica 1. Apertura comercial de México. 1895-2012

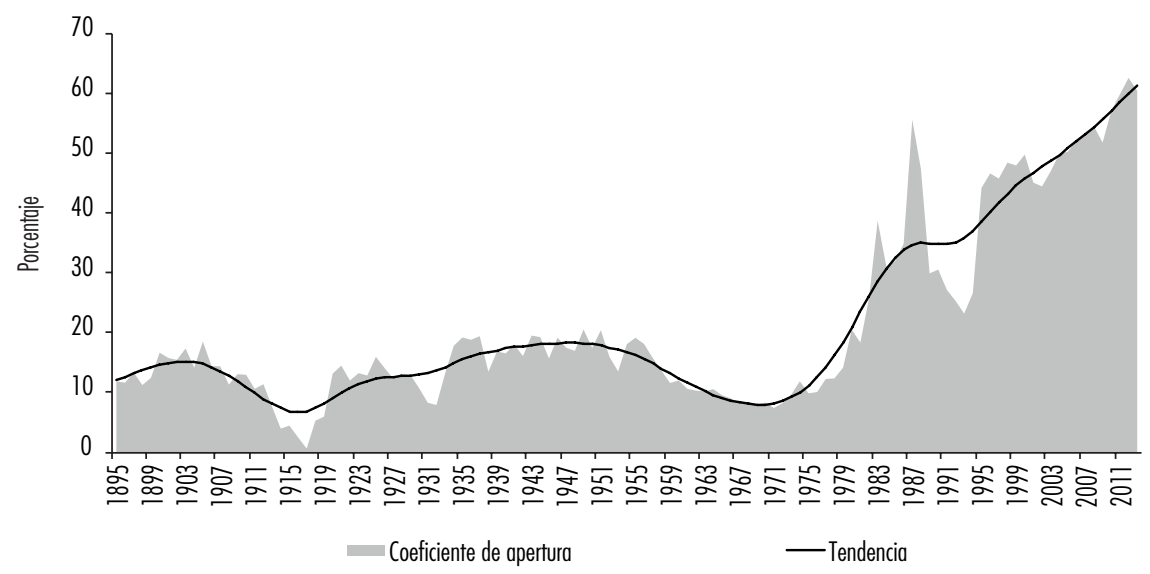

Fuente: Elaboración propia con base en el Sistema de Cuentas Nacionales de INEGI. Varios años. 


\section{RESULTADOS ECONÓMICOS CON DIFICULTADES POLÍTICAS DE UNA ECONOMÍA CON DESARROLLO Y CON CRECIMIENTO ESTABLE}

Los resultados de los procesos referidos, junto con otros que quedan fuera de este ensayo, han marcado con fuerza el perfil de esta época y es indudable que condicionan el presente y sus posibilidades: las exportaciones se multiplicaron por 10 y su composición cambió en favor de las manufacturas y en contra de las petroleras; otro tanto ocurrió con las importaciones que crecieron con celeridad.

Las regiones del centro norte y la frontera con Estados Unidos vieron crecer logarítmicamente su población y experimentaron una industrialización acelerada, sobre todo con base en la maquila.

Pero, por otro lado, el crecimiento del producto interno bruto (PIB) se redujo y trazó una trayectoria de largo plazo inferior a la de los 30 años previos. Entre 1933 y 1981, la economía creció 6.13\% anual en promedio; entre 1994 y $1999,2.24 \%$, y entre 2000 y 2008 también $2.24 \%$.

La formación de capital se redujo de haber tenido coeficientes por encima de $25 \%$ en los ańos setenta, a niveles apenas superiores a $20 \%$ en el periodo siguiente: la retracción de la inversión pública decidida en 1982 como parte del ajuste externo fue mantenida a todo lo largo del periodo sin haber sido compensada o sustituida por la inversión privada mexicana y foránea que se esperaba vendría gracias al cambio estructural y el TLCAN.

\section{Gráfica 2. Crecimiento de las importaciones 1980-2013}

Las importaciones mexicanas se multiplicaron por nueve entre 1980 y 2004 en términos reales, para 2013 la cifra anterior se duplicó.

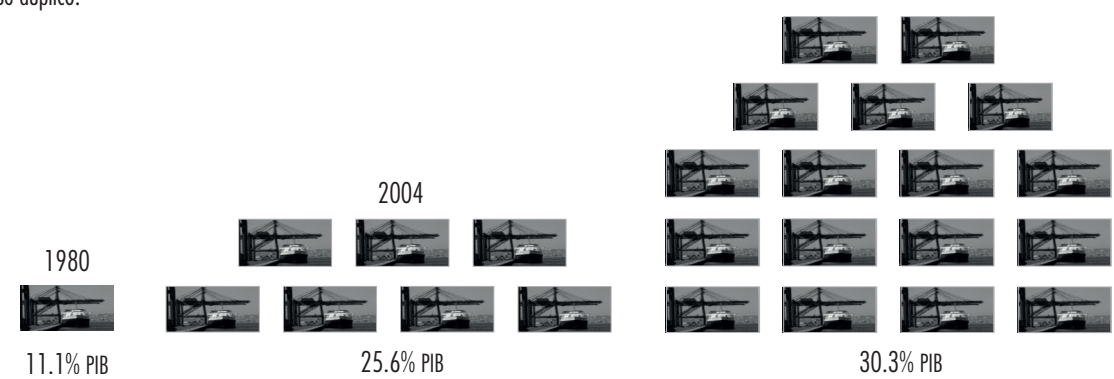

Fuente: Elaboración propia con base en el Sistema de Cuentas Nacionales de INEGI. Varios años. 


\section{Rolando Cordera}

Gráfica 3. Crecimiento y caracterización de las exportaciones 1980-2013
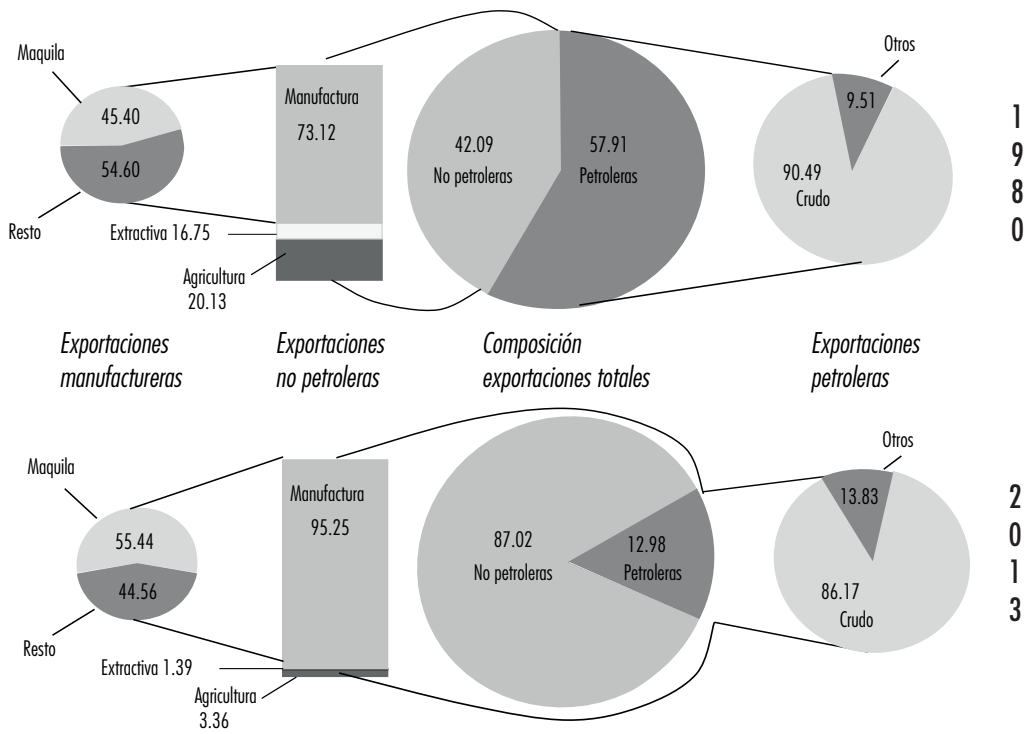

Fuente: Elaboración propia con base en el Sistema de Cuentas Nacionales de INEGI. Varios años.

Gráfica 4. Crecimiento del PIB 1922-2013

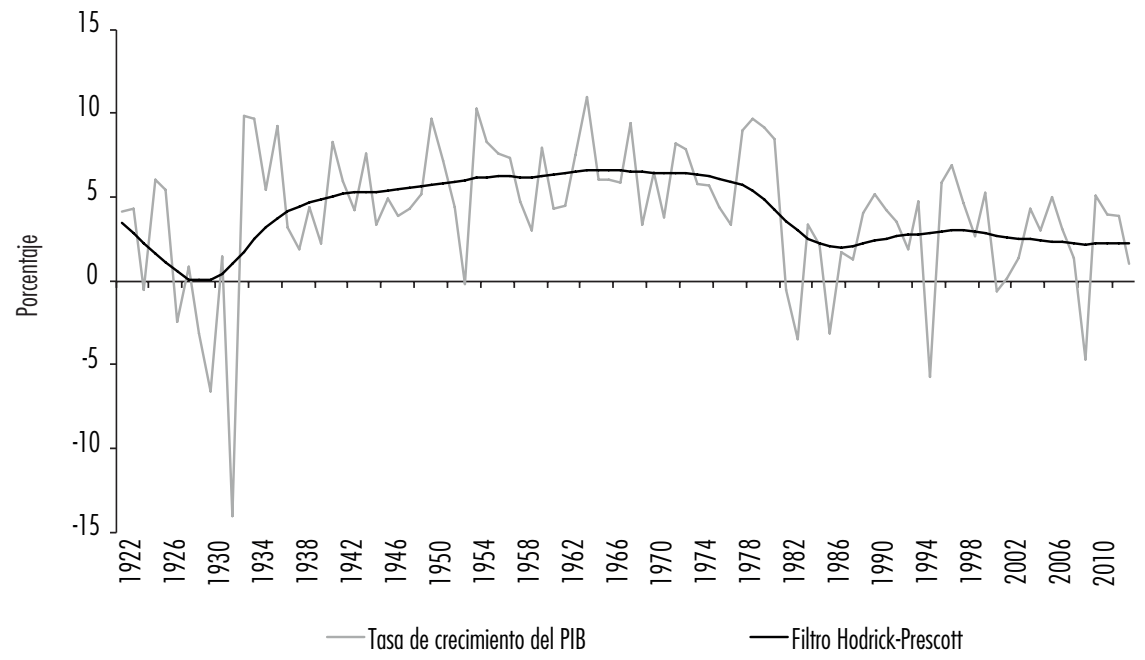

Fuente: Elaboración propia con base en el Sistema de Cuentas Nacionales de INEGI. Varios años. 
Gráfica 5. Formación bruta de capital fijo 1970-2012

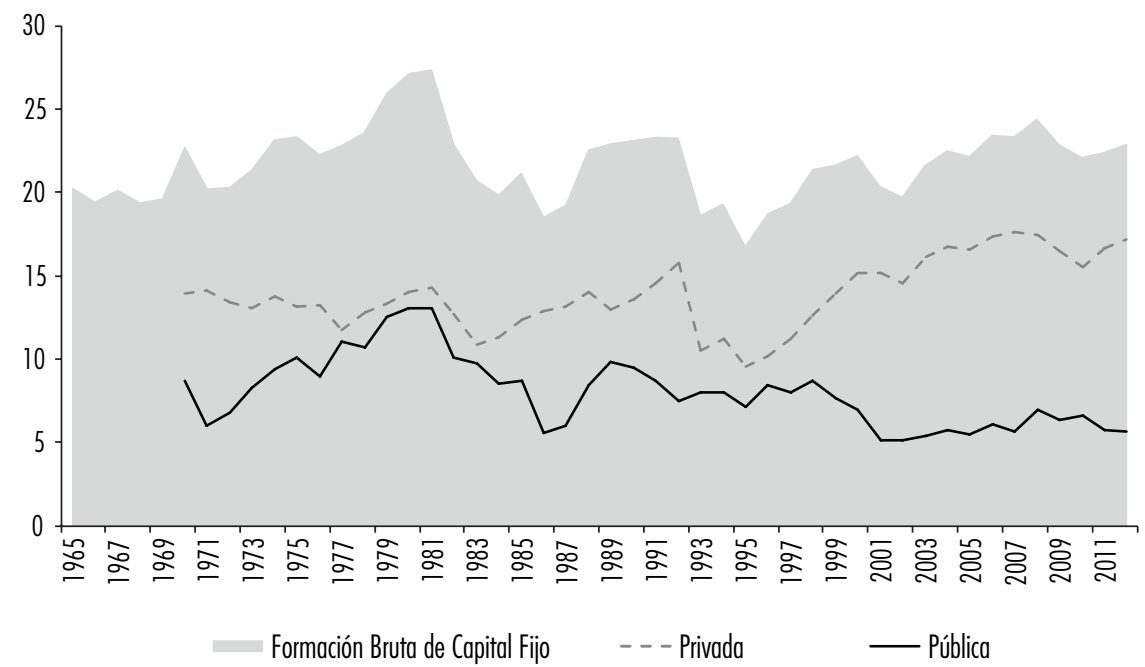

Fuente: Elaboración propia con base en el Sistema de Cuentas Nacionales de INEGI. Varios años.

\section{VULNERABILIDAD SOCIAL, POBREZA Y UN MEDIOCRE CRECIMIENTO}

El traído y llevado "bono demográfico", con el predominio de los jóvenes y los adultos jóvenes en la pirámide y la dinámica poblacionales, se ha diluido en la informalidad laboral, la emigración al norte y la inocupación juvenil que frecuentemente lleva a los jóvenes a la más cruel de las informalidades: la opción por el crimen organizado. La disonancia entre demografía y economía, siempre presente como probabilidad y expresada cotidianamente en los desajustes en el empleo y el mercado laboral en su conjunto, ha desembocado en un abierto y belicoso divorcio entre una economía que en efecto se transformó y una demografía que también lo hizo, pero no ha encontrado en tales transformaciones la posibilidad de ocupación, educación y salud que, en lo elemental, su mudanza biológica reclama.

La vulnerabilidad social se ha vuelto costumbre y la pobreza afecta a prácticamente la mitad de la población, sin conmoverse mayormente ante los programas dirigidos a su superación. Se ha impuesto una cultura de la pasividad social que ve como hechos naturales la concentración de la riqueza y el ingreso y el estancamiento, cuando no el deterioro, de los niveles de vida y bienestar de la mayoría de la población. 
Rolando Cordera

Gráfica 6. Bono demográfico en México 1950-2050

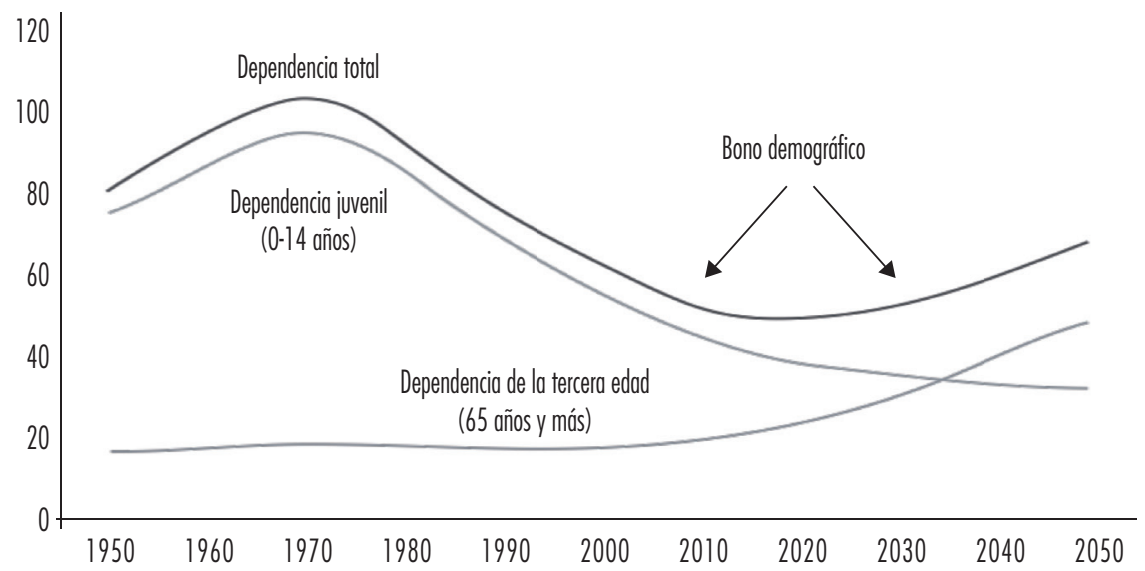

Fuente: Elaboración propia con base en Censos Poblacionales de INEGI y las Proyecciones de Población de Conapo. Varios años.

Gráfica 7. Pobreza multidimensional 2012

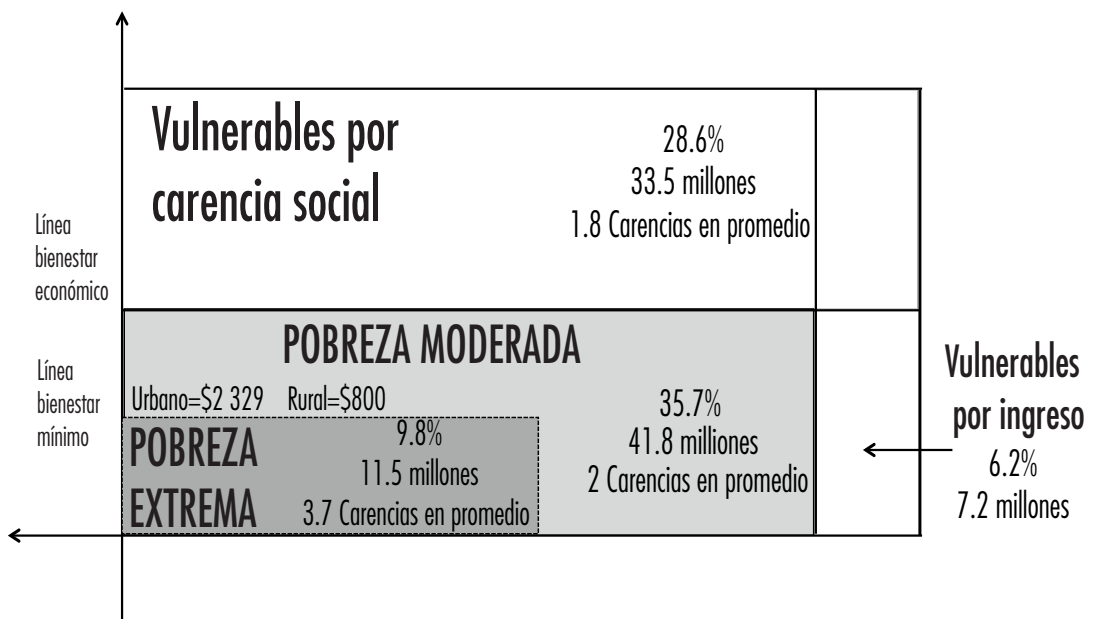

Fuente: Coneval 2013. 
Entre 2000 y 2010 , la fuerza de trabajo aumentó en 10 millones de personas, pero sólo 3 millones obtuvieron empleos formales, 4.3 millones se alojaron en la informalidad y el resto cayó en el desempleo. Sociedad de trabajadores, cuyas relaciones y satisfacciones pasan casi en su totalidad por el mercado y el dinero, México no ha podido crear las condiciones para mejorar como colectividad dentro de estos parámetros.

En 2001, el $10.30 \%$ de la población ocupada obtenía ingresos equivalentes a cinco o más salarios mínimos; en 2013, apenas $8.4 \%$ tenía ese nivel de ingresos, y $65 \%$ de los ocupados recibía ingresos iguales o menores a tres salarios mínimos.

Gráfica 8. Población ocupada según nivel de ingresos 2001-2013

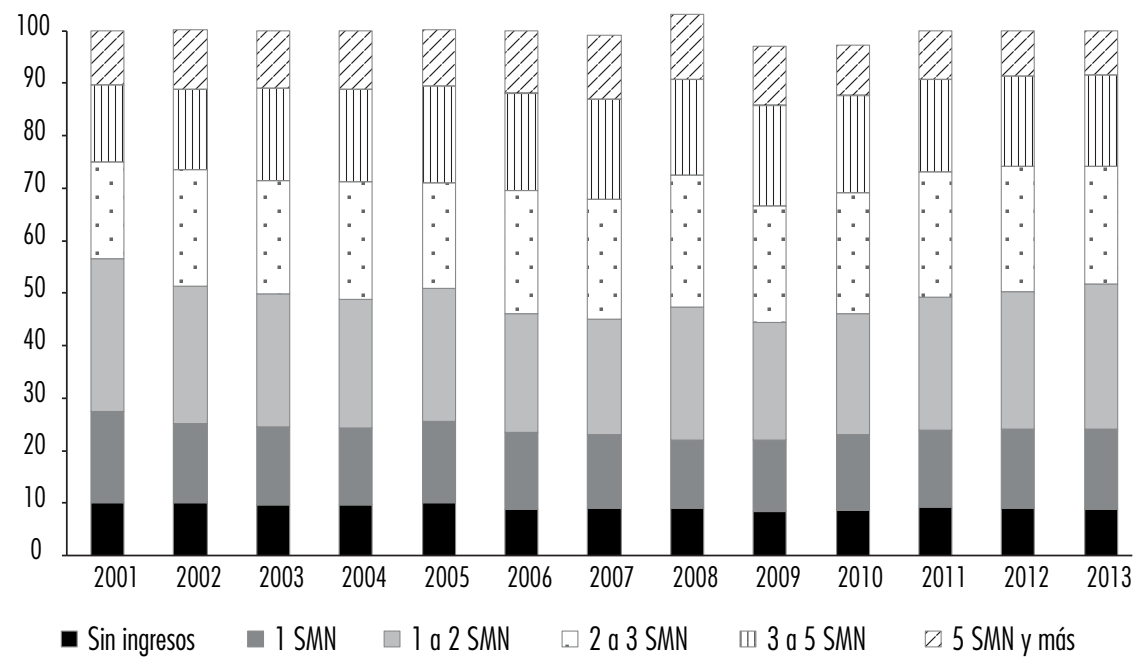

Fuente: Elaboración propia con base en la ENOE de INEGI. Varios años.

La gráfica anterior retrata un lento y "mediocre" crecimiento que, como se dijo, configura un divorcio letal con el otro, fundamental, gran cambio de la época: el demográfico que nos convirtió de "país de niños" a país de jóvenes y adultos jóvenes que hoy encarnan no el bono demográfico, sino su desperdicio en el desempleo, la informalidad, la mala educación, la emigración y la opción por la criminalidad. En particular el empleo tuvo el siguiente comportamiento en la primera década del siglo XxI. 
Gráfica 9. Población ocupada según nivel de ingresos 2001-2013

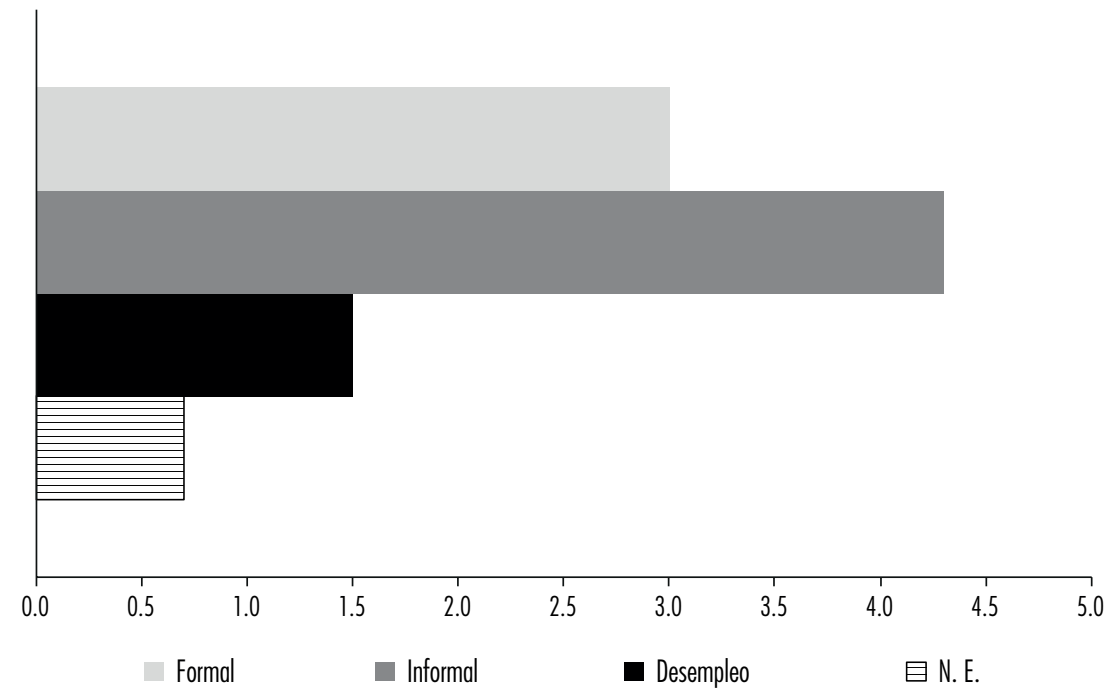

Fuente: Samaniego, 2011.

Tanto los resultados como el desempeño económico y social de México a lo largo de estos "30 dolorosos" ańos, ejemplifican con claridad la experiencia histórica de un cambio institucional drástico que no dio los frutos prometidos. Tampoco hizo emerger las estructuras y potencialidades que el país requiere para mantenerse como Estado nacional en medio de la globalización.

De hecho, hoy puede decirse que las condiciones técnicas e institucionales mínimas necesarias para que la nueva ronda de reformas estructurales rinda resultados positivos en materia económica y social no están claramente establecidas, ni sólidamente sustentadas en mecanismos y relaciones políticas y sociales capaces de acumular y encauzar las energías que dichas reformas pretenden desatar.

La "reforma de las reformas" que se proclamara como el punto de inflexión para un nuevo rumbo, después de la década perdida de los años ochenta, no pudo concretarse y en su lugar parece haberse optado, con precipitación y sin meditación, por el camino de las reformas sucesivas, de " $n$ " generaciones, que por ellas mismas no pueden asegurar el surgimiento de nuevos patrones de acumulación en que tiene que sustentarse la aspiración de recuperar la trayectoria histórica perdida en la última década del siglo xx. 
En estos años, no ha habido desarrollo porque el crecimiento ha sido insuficiente y la redistribución social y de ingresos quedó al margen de la estrategia y sus políticas, pero también de los movimientos y reclamos de la sociedad. La "Gran Transformación” mexicana, para recordar a Polanyi (1992), aterrizó en un estancamiento histórico relativo y no en la dinamización económica y el reforzamiento de la cohesión social fruto de la democracia y el bienestar comunitario.

\section{TLCAN Y EL PROFUNDO PROCESO DE INTERNACIONALIZACIÓN ACOMPAÑADO DE UNA RECONFIGURACIÓN DEL PODER}

Las creaturas simbólicas y culturales, junto con las nuevas configuraciones del poder que la pluralidad y la internacionalización de nuestra economía política han prohijado, están aquí y ahora. Su resultado es causa y consecuencia del TLCAN. Han condicionado y determinado nuestras perspectivas y el diseño de las opciones y alternativas que pudieran trazar una trayectoria distinta a la reseñada.

Para bien o para mal, el Tratado ya ha dado lo que tenía que dar, así lo manifiesta Gazol (2014), pero los miles de kilómetros de frontera seguirán ahí como también lo hará la intensa y, en no pocas ocasiones tensa, relación con Estados Unidos, algunas preguntas a plantearnos en esta tesitura podrían ser: ¿Será gobernada por la inercia esa relación?, ¿por las fuerzas del mercado?, ¿por quién?, ¿cómo?, ¿hacia dónde? o ¿̇no será gobernada? La elite gobernante tendrá una respuesta para enfrentar esta situación desde el ámbito económico, político y social para revertir la "Gran Transformación".

Jorge Castañeda (2014) adelantaba una respuesta: "A pesar de los resultados decepcionantes del Tratado, tal vez México necesita más TlC y no menos"; sin embargo, "más TLC y no menos", admite varios significados e implicaciones, no pocos de ellos contradictorios si se incorpora a la propuesta el complicado inventario político y social de ambas sociedades. El futuro de una integración efectiva y expresamente buscada en dirección de un mercado común norteamericano, por ejemplo, no puede separarse de los grandes desafíos condensados en la cuestión social mexicana y muy afectada por la crisis actual en Estados Unidos (Cordera, 2010: 32).

Por lo demás, en medio y a través de las grandes dislocaciones que ha traído consigo la Gran Recesión, tanto México como Canadá y Estados Unidos exploran otras vías de integración comercial y financiera lo que hace de la globalización presente un panorama abigarrado donde sus escenarios no son 
claros para visiones integracionistas como las que acompañarían una proyección más o menos lineal del actual TLCAN.

Más allá de centrar la discusión en si más o menos Tratado, lo que a México le urge es un nuevo curso de desarrollo; uno que nos permita ser capaces de interiorizar las ganancias del comercio exterior que trajeron la apertura y la extensión parcial, pero eficaz del "capitalismo asociado" inaugurado en los años sesenta, con la energía, la maquila y la industria automotriz.

El desafío radica en nacionalizar la globalización para administrar sus "trilemas", como los ha llamado Rodrik (2012). De aquí la importancia crucial de la soberanía y la democracia. Si hubiera que decirlo en una nuez, habría que afirmar que pecamos de omisión en dos aspectos fundamentales:

1) Que para un país en desarrollo, las exportaciones no son un fin en sí mismo, sino que deben servir para incrementar su capacidad para importar; $y$

2) Que estas importaciones sólo podrán rendir su servicio al desarrollo si se inscriben en un proyecto nacional de industrialización. En fin, que como dijera Romano Prodi: no hay éxito exportador que dure sin un mercado interno robusto, y no puede haber mercado interno alguno sin política industrial.

Entre los temas de la agenda de este nuevo curso están, por mencionar algunos, la relación entre la política industrial y la apertura (Tello, 2007: 738); qué Estado fiscal para un nuevo desarrollismo, para la equidad y el crecimiento para la igualdad. Liberar la imaginación de la política macroeconómica para hacer que la apertura nos favorezca, como recientemente planteó MorenoBrid (2013).

\section{REFLEXIÓN}

Revisar nuestras pautas mentales y económicas de integración al mundo, adoptadas a fin de siglo con activismo y audacia, pero con una profunda reflexión estratégica. Ser capaces de conjugar creativamente la igualdad con la democracia, como el faro de un nuevo cambio estructural y del proceso mismo de integración de México a los nuevos mundos globalizantes después de la crisis. Pensar en los renglones de la agenda para revertir la "Gran Transformación” del milagro mexicano. Hoy el pensamiento de Polanyi inspira una mayor justicia social, revertir la austeridad y el estancamiento frente a un mundo sin crecimiento con ansias de terminar con las desigualdades en un régimen democrático. 


\section{BIBLIOGRAFÍA}

Castañeda, Jorge (2014), "Más tlc y no menos", Nexos, núm. 433, enero, pp. 32.

Cordera, Rolando (2010), México frente a la crisis. Hacia un nuevo curso de desarrollo, México, unam.

Cordera, Rolando y Carlos Tello (1981), La disputa por la nación. Perspectivas y opciones del desarrollo, México, Siglo XXI Editores.

Gazol, Antonio (2014), "Sobres las culpas del TLCAN", en "El Correo del Sur" (suplemento), La Jornada de Morelos, 12 de enero (consultado el 20 de noviembre), disponible en <http://periodicocorreodelsur.com/sobre-lasculpas-del-tlcan/>

Moreno-Brid, Juan Carlos (2013), "Política macroeconómica para el desarrollo", Economía UNAM, núm. 30, México, septiembre-diciembre.

Novelo, Federico (2012), "El contexto internacional", en Ricardo Becerra (coord.), Equidad social y parlamentarismo. Balance de treinta años, México, Instituto de Estudios para la Transición Democrática y Siglo XXI Editores, pp. 39-66.

Polanyi, Karl (1992), La gran transformación. Crítica del liberalismo económico, México, Fondo de Cultura Económica.

Rodrik, Dani (2012), La paradoja de la globalización. Democracia y el futuro de la economía mundial, España, Antoni Bosch editor.

Serra Puche, Jaime (1992), Conferencia. Universidad Iberoamericana. 19 de marzo de 1992.

Tello, Carlos (2007), Estado y desarrollo económico: México 1920-2006, México, Facultad de Economía, unAm. 
